\title{
AÇÃO AFIRMATIVA EM UMA ESCOLA MÉDICA NO BRASIL: PERSPECTIVAS DOS ESTUDANTES
}

\author{
AFFIRMATIVE ACTION IN A MEDICAL SCHOOL IN BRAZIL: STUDENTS' \\ PERSPECTIVES \\ ACCIÓN AFIRMATIVA EN UNA ESCUELA MÉDICA EN BRASIL: PERSPECTIVAS DE \\ LOS ESTUDIANTES
}

\author{
Luciana Almeida Silva Teixeira \\ E-mail: luciana.teixeira@uftm.edu.br \\ Morgana Oliveira Couto \\ E-mail: morgana4oliveira@gmail.com \\ Patrícia Vaz Lima Santos \\ E-mail: patriciavazdelima@yahoo.com.br \\ Universidade Federal do Triângulo Mineiro - UFTM
}

\section{RESUMO}

O Sistema de Seleção Unificada (SISU) constitui atualmente a forma de seleção unificada nas instituições federais no Brasil. Em paralelo, a entrada de estudantes por meio de ação afirmativa foi ampliada para garantir a inserção de alunos de escolas públicas. Em 2014, a Universidade Federal do Triângulo Mineiro (UFTM) adotou $50 \%$ das vagas destinadas para ação afirmativa (socioeconômica e racial). O presente estudo foi realizado com a primeira turma do Curso de Medicina da UFTM com a utilização de $50 \%$ das vagas com entrada por ação afirmativa. Após dois anos de curso, os estudantes responderam questões referentes ao seu envolvimento em atividades extracurriculares e auto percepção de ganho de conhecimentos/habilidades no período. Para a maioria dos aspectos perguntados, não houve diferença entre os estudantes. Os alunos cuja entrada ocorreu por meio de ação afirmativa foram significativamente mais frequentes nos itens: recebimento de auxílio estudantil e percepção dos determinantes sociais, com reconhecimento do papel do médico. Conclui-se que a entrada por meio de ação afirmativa não interferiu no acesso a atividades extracurriculares no grupo estudado.

PALAVRAS-CHAVE: Ação afirmativa. Escola Médica. Ingresso.

\section{ABSTRACT}

The Sistema de Seleção Unificada (SISU) is currently the form of unified selection in federal institutions in Brazil. In addition, the entry of students through affirmative action was expanded to ensure the inclusion of students from public schools. In 2014, 50\% of the access in Triângulo Mineiro Federal University was destined for affirmative action (socioeconomic and racial). The present study was performed with the first medicine students group for which this rule has been applied. After two years at medical school, the students answered questions related to their involvement in extracurricular activities and self-perception of knowledge / skills gain in the period. For most of the questions asked, there was no difference between the students. The students whose entry occurred through affirmative action were significantly more frequent in the items: receipt of student aid and perception of social determinants, with recognition of the role of the physician. It was concluded that the entrance through affirmative action did not interfere in the access to extracurricular activities in the studied group.

KEYWORDS: Affirmative action. Medical School. Entrance.

\section{RESUMEN}

El Sistema de Seleção Unificada (SISU) constituye actualmente la forma de selección unificada en las instituciones federales en Brasil. En paralelo, la entrada de estudiantes por medio de acción afirmativa fue ampliada para garantizar la inserción de alumnos de escuelas públicas. En 2014, la Universidad Federal del Triángulo Minero (UFTM) adoptó el 50\% de las vacantes destinadas a la acción afirmativa (socioeconómica y racial). El presente estudio fue realizado con la primera clase del Curso de Medicina de la UFTM con la

v.11

n. 3

p. $129-138$ Set. / Dez. 
utilización del 50\% de las vacantes con entrada por acción afirmativa. Después de dos años de curso, los estudiantes respondieron cuestiones referentes a su participación en actividades extracurriculares y auto percepción de ganancia de conocimientos / habilidades en el período. Para la mayoría de los aspectos preguntados, no hubo diferencia entre los estudiantes. Los alumnos cuya entrada ocurrió por medio de acción afirmativa fueron significativamente más frecuentes en los items: recepción de ayuda estudiantil y percepción de los determinantes sociales, con reconocimiento del papel del médico. Se concluye que la entrada por medio de acción afirmativa no interfirió en el acceso a actividades extracurriculares en el grupo estudiado.

PALABRAS-CLAVE: Acción afirmativa. Escuela Médica. Examen de ingreso.

\section{INTRODUÇÃ̃O}

O acesso ao ensino superior público no Brasil passou por diversas transformações ao longo do tempo. O presente estudo busca identificar se existe diferença no desempenho acadêmico ao longo da graduação entre estudantes que ingressaram no Curso de Medicina da UFTM por meio de cotas, quando comparado com os que entraram nas vagas de ampla concorrência.

\section{REFERENCIAL TEÓRICO}

A década de 1960 foi marcada pela ampliação de vagas principalmente por meio da abertura e expansão das universidades privadas. Este processo, no entanto, não foi suficiente para fazer com que o país deixasse de possuir uma das mais baixas taxas de escolarização bruta na Educação Superior da América Latina. Concomitantemente, foi observada a elitização do perfil dos alunos, principalmente nos cursos mais concorridos e nas instituições públicas, onde é muito pequena a presença de alguns grupos, que podem ser considerados como minorias. Faz-se importante salientar que a expansão no número de IES brasileiras não representou uma forma de promoção do acesso de estudantes oriundos de segmentos socioeconômicos mais baixos. (ALVARENGA et al, 2012; ANDRIOLA 2011).

Pesquisas educacionais têm demonstrado que alunos oriundos de escolas públicas obtêm mais sucesso nos processos seletivos das instituições de ensino superior privadas, enquanto os provenientes de escolas particulares, em sua maioria, conseguem êxito nos processos seletivos das instituições públicas de ensino superior. A dualidade escola privada e escola pública tem sido utilizada para explicar em parte as diferenças de desempenho dos candidatos na seleção à educação superior. (BORGES, 2005)

Algumas universidades, como a Universidade de Brasília (UnB), adotaram o Programa de Avaliação Seriada (PAS), além do vestibular tradicional, a fim de minimizar a reprodução da estratificação social no ensino superior. No entanto, percebeu-se que, pelo menos nos cursos mais concorridos, como Direito, Medicina e Engenharia Civil, a aprovação no PAS estava relacionada com melhores condições socioeconômicas e culturais dos candidatos. (BORGES, 2005).

Em 2007 o governo implantou o Plano de Reestruturação e Expansão das Universidades Federais (REUNI), com o objetivo de levar universidades para regiões mais distantes e 
carentes o Brasil. No entanto, o perfil dos ingressantes no ensino superior não se alterou. (ANDRIOLA, 2011)

O Exame Nacional do Ensino Médio (ENEM), criado em 1998, objetivava, inicialmente, avaliar o desempenho dos estudantes ao fim da escolaridade básica. Após a prova sofrer alterações, em 2010, o MEC propôs utilizar o novo ENEM também como forma de seleção unificada nos processos seletivos das Instituições Federais de Ensino Superior (IFES), a fim de democratizar as oportunidades de acesso às vagas federais de ensino superior. Assim, foi criado o Sistema de Seleção Unificada (SISU), no qual as IFES participantes selecionam os novos estudantes pela nota obtida no ENEM. (ANDRIOLA, 2011)

Ainda, para modificar essa realidade, houve a implantação das cotas nas universidades federais do país, de modo a promover a inserção dos alunos de escolas públicas em tais instituições. Essa questão ainda é um tema muito polêmico no país. Há quem considere que as cotas significam uma reparação histórica e justiça social para aquela parcela da sociedade economicamente excluída. No entanto, há aqueles que questionam a capacidade dos estudantes cotistas de acompanharem o curso, já que eles não tiveram uma boa base escolar no ensino médio. Além disso, há quem defenda que a adoção de cotas consiste no abandono à meritocracia e um risco para a manutenção da qualidade do ensino superior público.

\section{MATERIAIS E MÉTODOS}

Os estudantes da turma 78 do Curso de Medicina da UFTM, cujo ingresso ocorreu no primeiro semestre de 2014, foram convidados a participar do estudo. Ao final do segundo ano na universidade, em dezembro de 2015, os alunos foram esclarecidos dos objetivos da pesquisa e, os que concordaram, assinaram o Termo de Consentimento Livre e Esclarecido. A seguir, foram aplicados dois questionários para preenchimento individual nos quais constavam as seguintes variáveis:

Questionário 1: variáveis relativas à participação dos universitários em atividades extracurriculares e recebimento de auxílio financeiro durante a graduação.

Questionário 2: variáveis relativas à auto percepção sobre a própria aquisição de competências e habilidades, com base nas competências previstas no Projeto Pedagógico do Curso de Medicina da UFTM. Optou-se pelo questionário retrospectivo de auto percepção antes e depois da atividade. Este método mostrou-se eficaz quando comparado à aplicação de dois instrumentos (antes e depois) para avaliar uma intervenção educacional (BANJHI et al, 2012). No presente estudo, o estudante assinalava, numa escala de 0 a 3 pontos, sua percepção de competência antes e depois da intervenção, no caso estar no curso de medicina, com relação aos objetivos educacionais previstos no projeto pedagógico. A escala foi definida como: 0 = nenhuma competência; 1 = pouca competência; $2=$ competente; 3 = expert. Os itens avaliados foram extraídos literalmente como estavam redigidas como competências esperadas para os estudantes de medicina no PPC do curso. Ao final deste questionário, foram realizadas duas perguntas: "Você se sente em desvantagem em termos de conhecimento prévio necessário na universidade em relação a outros colegas? Você acredita possuir um 
método de estudo adequado?”, cuja resposta variava na escala likert entre: Não, Muito Pouco, Pouco, Razoavelmente e Muito. Também foi deixado um espaço em branco para algum registro que o estudante quisesse se manifestar.

Os dados obtidos foram avaliados por meio de análise descritiva. Para os dados numéricos categóricos a comparação entre duas proporções foi feita por meio do teste quiquadrado, se o número total de amostras avaliadas fosse maior que 40. Quando o número de amostras estava entre 21 e 40 e todas as células apresentavam valores maior que 5, foi feito o teste quiquadrado com correção de Yates. Nos casos onde número de amostras fosse igual ou menor que 20 ou alguma célula tivesse valor menor que 5, foi empregado o teste exato de Fisher. Para todos estes testes não paramétricos foram utilizados grau de liberdade de $1 \mathrm{e}$ intervalo de confiança de $95 \%$. As análises foram feitas no programa STATISTICA 6.0.

O presente projeto respeitou a Resolução 466/12 que estabelece os princípios éticos para a condução de pesquisas com seres humanos, e foi aprovado no Comitê de Ética em Pesquisa da UFTM sob o número de registro: CAAE: 51657915.0.0000.5154.

\section{ANÁLISE DOS DADOS E RESULTADOS}

A turma convidada para participar do estudo é composta por 36 alunos dos quais 35 concordaram e responderam aos questionários. Dentre os participantes, 18 (51,4\%) ingressaram por meio de vagas de ampla concorrência (AC) e $17(48,6 \%)$ de vagas de ações afirmativas (AA). Dez alunos (28,6\%) selecionados por meio das AA, o foram por possuir renda familiar mensal inferior a 1,5 salários mínimos.

Todas as informações obtidas se referiam ao intervalo de tempo entre que o $1^{\mathrm{o}}$ e $5^{\mathrm{o}}$ período de graduação no curso de Medicina da UFTM.

Com relação ao primeiro questionário, não houve diferença significativa entre o tipo de ingresso na universidade e os quesitos de participação em diversas atividades extracurriculares, apresentação de trabalhos ou mesmo recebimento de bolsas. A única variável com diferença estatisticamente significante foi o recebimento de auxílio estudantil, mais frequente entre os estudantes com entrada via AA, como verificado na Tabela 1.

Tabela 01: Comparação entre o tipo de ingresso na universidade de o acesso a atividades extracurriculares e recebimento de recursos

\begin{tabular}{l|c|c}
\hline \multicolumn{2}{c}{} & \multicolumn{2}{c}{ Tipo de ingresso } \\
\cline { 2 - 3 } \multicolumn{2}{c}{$\begin{array}{c}\text { Ampla } \\
\text { Concorrência } \\
(\mathbf{n = 1 8 )}\end{array}$} & $\begin{array}{c}\text { Ações } \\
\text { Afirmativas } \\
(\mathbf{n = 1 7 )}\end{array}$ \\
\hline Quesito & 15 & 15 \\
\hline Participação & 11 & 11 \\
\hline Eventos científicos & 7 & 11 \\
\hline Monitoria & 12 & 9 \\
\hline Pesquisa & &
\end{tabular}




\begin{tabular}{l|c|c}
\hline \multicolumn{1}{c|}{ Curso de idioma } & 6 & 8 \\
\hline Apresentação de trabalho & 2 & 6 \\
\hline \multicolumn{2}{|l}{ Recebimento de recurso } & 11 \\
\hline $\begin{array}{c}\text { Bolsa (monitoria e/ou } \\
\text { iniciação científica } \\
\text { e/ou extensão) }\end{array}$ & 11 & \\
\hline Auxílio estudantil* & 2 & 10 \\
\hline
\end{tabular}

* Diferença com significância estatística, $p=0,003$ (Teste Exato de Fisher)

Para análise do segundo questionário, o ganho de conhecimento/ habilidades foi mensurado por meio do gradiente entre como o estudante se auto avaliava antes e depois do período de dois anos na universidade, para cada um dos itens. Assim, foi considerado como presença de ganho quando o estudante atribuiu aumento igual ou superior a um ponto no número da escala de competência. Houve percepção dos estudantes de ganho de conhecimento/habilidade para todos os itens listados, como pode ser visto na Tabela 2. Chamou atenção a diferença estatisticamente significativa para maior percepção entre os estudantes cotistas para ganho no item: "Compreender os determinantes sociais, culturais, econômicos, biológicos e políticos do processo saúde-doença e da função médica".

Tabela 02: Comparação entre o tipo de ingresso na universidade e a auto percepção de conhecimento/habilidades ao longo de dois anos do curso

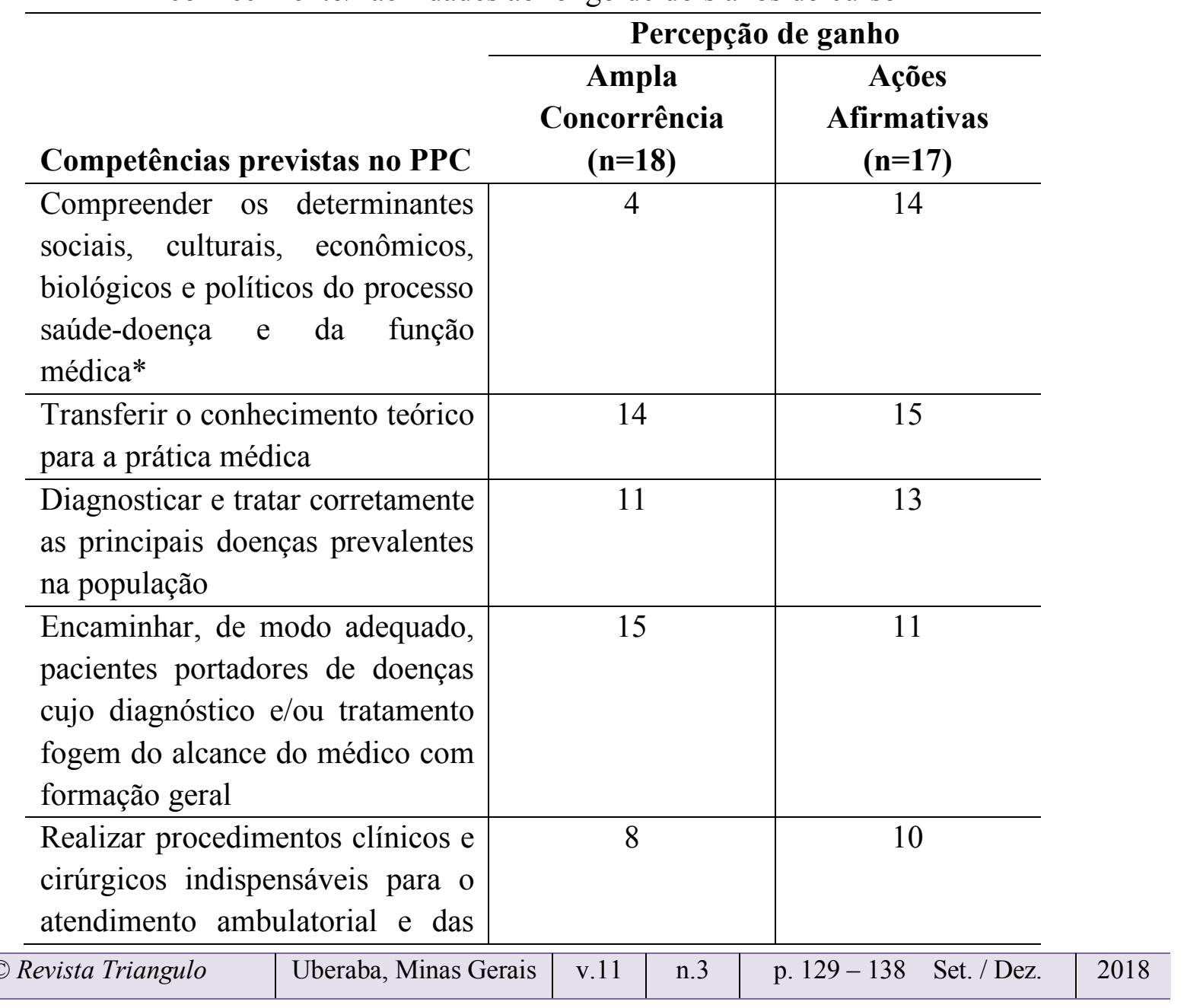




\begin{tabular}{|c|c|c|}
\hline urgências e emergências & & \\
\hline $\begin{array}{l}\text { Promover estilos de vida } \\
\text { saudáveis, atuando como agente } \\
\text { de transformação social }\end{array}$ & 12 & 13 \\
\hline $\begin{array}{l}\text { Atuar nos diferentes níveis de } \\
\text { atendimento à saúde, com ênfase } \\
\text { nos atendimentos primário e } \\
\text { secundário }\end{array}$ & 12 & 11 \\
\hline $\begin{array}{l}\text { Informar e educar seus pacientes, } \\
\text { familiares e comunidade em } \\
\text { relação à promoção da saúde, } \\
\text { prevenção, tratamento e } \\
\text { reabilitação das doenças, usando } \\
\text { técnicas apropriadas } \\
\text { comunicação }\end{array}$ & 16 & 14 \\
\hline $\begin{array}{l}\text { Realizar com proficiência a } \\
\text { anamnese e a consequente } \\
\text { construção da história clínica, } \\
\text { bem como dominar a arte e a } \\
\text { técnica do exame físico }\end{array}$ & 15 & 15 \\
\hline $\begin{array}{l}\text { Dominar os conhecimentos } \\
\text { científicos básicos da natureza } \\
\text { bio-psico-socioambiental } \\
\text { subjacentes à prática médica e ter } \\
\text { raciocínio crítico na interpretação } \\
\text { dos dados, na identificação da } \\
\text { natureza dos problemas da prática } \\
\text { médica e na sua resolução }\end{array}$ & 13 & 15 \\
\hline $\begin{array}{l}\text { Otimizar o uso dos recursos } \\
\text { propedêuticos, valorizando o } \\
\text { método clínico em todos seus } \\
\text { aspectos }\end{array}$ & 10 & 11 \\
\hline $\begin{array}{l}\text { Utilizar adequadamente recursos } \\
\text { semiológicos e terapêuticos, } \\
\text { validados cientificamente, } \\
\text { contemporâneos, hierarquizados } \\
\text { para atenção integral à saúde, no } \\
\text { primeiro, segundo e terceiro } \\
\text { níveis de atenção }\end{array}$ & 13 & 11 \\
\hline $\begin{array}{l}\text { Reconhecer a saúde como direito } \\
\text { e atuar de forma a garantir a } \\
\text { integralidade da assistência }\end{array}$ & 11 & 11 \\
\hline
\end{tabular}






* Diferença com significância estatística, p=0,0005 (Teste Exato de Fisher)

No que se refere à pergunta: "Você se sente em desvantagem em termos de conhecimento prévio necessário na universidade em relação a outros colegas?” nenhum estudante respondeu "Muito", quatro responderam "Razoavelmente" (todos do grupo AA), oito responderam "Pouco" (4 AC; 4 AA); 18 marcaram "Muito pouco" (13 AC; 5 AA) e cinco responderam "Não" (1 AC; 4 AA). Para a pergunta: "Você acredita possuir um método de estudo adequado?" quatro responderam que "Muito adequado" (1 AC; 3 AA); 17 consideraram "Razoavelmente adequado" (9 AC; 8 AA); nove responderam "Pouco adequado" (5 AC; 4 AA) e cinco marcaram "Muito pouco adequado" (3 AC; 2 AA). O pequeno número de indivíduos em cada categoria prejudicou a análise estatística das diferenças encontradas.

Apenas dois estudantes registraram opiniões no espaço aberto, um do grupo AA e o outro do grupo AC. Seguem os registros na íntegra:

Não acho que estou atrás dos colegas em relação a conhecimento prévio, porque embora eu seja egresso de escola pública, pude desenvolver essas habilidades ao longo de 3 anos de cursinho. Julgo meu método de estudo na faculdade ineficiente porque retenho mais conteúdo com questões do que com leitura. (estudante do grupo AA)

Acredito que pode existir diferenças entre o desempenho individual de acordo com a modalidade de ingresso na universidade, mas que essa diferença já é resolvida ainda no primeiro período, em que o melhor desempenho parte do maior empenho de cada um. (estudante do grupo AC)

Existe dúvida no que se refere a possíveis diferenças de desempenho acadêmico na universidade entre os estudantes que ingressam por meio das cotas, e os que ingressam na ampla concorrência. Argumenta-se que a base oferecida no ensino médio do estudante de escola pública seria insuficiente para que o mesmo conseguisse acompanhar o conteúdo do curso de graduação. Em contrapartida, esses estudantes poderiam se sentir mais motivados e se esforçarem mais, o que resultaria num maior "ganho relativo" quando comparado com os estudantes advindo de escolas privadas. Ademais, outro aspecto discutido é se existe diferença segundo o curso de graduação no qual o estudante se inseriu, por exemplo: aquele que ingressou no curso de engenharia dependeria mais do conhecimento prévio da matemática quando comparado com o que ingressou para o curso de medicina, para o qual os conhecimentos prévios pouco auxiliariam.

Segundo Alvarenga et al, considerando indicadores quantitativos, não houve uma grande diferença no desempenho dos alunos. Em alguns cursos, os universitários que estudaram o ensino médio em escolas públicas obtiveram coeficiente de rendimento acadêmico superior àqueles de escolas particulares. Os alunos que participaram da pesquisa disseram não acreditar que tinham que se esforçar mais em relação aos colegas; a dificuldade que apresentavam era devido ao rigor dos professores e à dificuldade do conteúdo. No entanto, foi 
ressaltada que a diferença socioeconômica entre os dois tipos de estudantes seria um fator que exige maior esforço dos alunos que estudaram em escolas públicas (ALVARENGA et al, 2012).

No estudo de Maia et al, a pesquisa foi realizada calculando-se o ganho relativo, que consiste na diferença da colocação do aluno, dentro de sua turma, com relação ao coeficiente de rendimento final e a sua colocação com relação à nota final padronizada do vestibular. $\mathrm{O}$ estudo identificou que os universitários que estudaram o ensino médio em escolas públicas apresentaram um ganho relativo médio maior quando comparado aos estudantes de escolas particulares (MAIA et al, 2009). Resultado semelhante foi semelhante ao de Wainer et al, que apontam em conclusão:

Não há diferença prática entre o conhecimento de alunos cotistas e o de seus colegas de classes não cotistas ao final do curso, se assumirmos que o exame do Enade mede o tanto habilidades gerais de raciocínio como conhecimentos específicos do curso. Não há diferença prática entre o conhecimento de alunos cotistas por razões raciais ou sociais e o de seus colegas de classes que não são cotistas. Não há diferença prática de conhecimentos entre cotistas e não cotistas em classes com média alta nos exames de conhecimento específico. (WAINER et al, 2017, p. 13)

No presente estudo, foi verificado que estudantes cotistas e não cotistas tiveram oportunidades semelhantes de desenvolver ações extracurriculares, o que pode sinalizar que não houve diferença entre a capacidade dos mesmos buscarem oportunidades educacionais dentro da universidade. Assim, não foram identificados prejuízos associados à condição de entrada neste grupo de estudantes. Assim, estes resultados são concordantes com os estudos acima referidos.

Em contrapartida, Mendes Júnior encontrou que em relação aos coeficientes de rendimento (CR), houve pior desempenho entre os cotistas, principalmente em cursos com alta dificuldade relativa. Por outro lado, ressaltou que houve menor taxa de evasão entre os estudantes cotistas, o que o levou a afirmar:

Ao contrário do que poderíamos esperar, a política de cotas trouxe para a sociedade dois comportamentos contrários. Um positivo, através de maiores taxas de graduação e um negativo, resultado de coeficientes de rendimento menores. (MENDES JUNIOR, 2014, p. 52)

A taxa de evasão do curso de medicina é muito baixa, e essa informação não pode ser comparada com nossos resultados. Ademais, a análise de uma única turma é insuficiente para estudar essa variável.

Um aspecto chamou atenção no grupo de estudantes cotistas do presente estudo, a significativa maior percepção de ganho de conhecimento no item referente a "Compreender os determinantes sociais, culturais, econômicos, biológicos e políticos do processo saúdedoença e da função médica". Isso pode sinalizar a entrada de estudantes mais conectados com a realidade social, bem como ao papel do médico neste contexto.

Mesmo sem significância estatisticamente identificada, foi possível constatar que quatro estudantes cotistas se sentiram razoavelmente em desvantagem em termos do conhecimento prévio necessário na universidade, em relação a outros colegas. Para Neves et al, discussões 
sobre as cotas universitárias precisam incorporar o conceito de reconhecimento social dos estudantes. Em seu estudo refere que:

As cotas aparecem nos discursos como uma oportunidade de entrada no ensino universitário, abrindo novas possibilidades de vida e de ascensão social. A desmistificação do acesso à universidade influenciou na decisão de prestar a seleção e cumpriu um papel importante para vencer o complexo de inferioridade, que existia até então. Além disso, o respeito obtido dos outros seria a outra face da valorização de si e dos esforços individuais para entrar na universidade, em oposição aos jovens oriundos das classes mais abastadas, que teriam tido condições de vida mais favoráveis ao estudo. (NEVES et al, 2014, p. 52)

Os estudantes do presente estudo pouco se manifestaram na questão aberta, sendo as respostas direcionadas à percepção de não diferença entre os grupos. Cabe ressaltar que este estudo não objetivou aprofundar em tais questões.

\section{CONSIDERAÇÕES FINAIS}

Em conclusão, foi possível constatar que não houve diferença significativa entre o acesso às oportunidades extracurriculares entre o grupo de estudantes de medicina cotistas e não cotistas estudados. Ademais, os estudantes cotistas poderiam estar mais propensos a se interessarem pelos determinantes sociais das doenças, bem como em compreender o papel do médico nesse processo.

\section{REFERÊNCIAS}

ALVAREnGA, C. F. et. al. Desafios do Ensino Superior para Estudantes de Escola Pública: um Estudo na UFLA. Revista Pensamento Contemporâneo em Administração. Rio de Janeiro, v. 6, n. 1, p. 55-71, jan./mar, 2012.

ANDRIOLA, W. B. Doze motivos favoráveis à adoção do Exame Nacional do Ensino Médio (ENEM) pelas Instituições Federais de Ensino Superior (IFES). Ensaio: aval. pol. públ. Educ., Rio de Janeiro, v. 19, n. 70, p. 107-126, jan./mar. 2011

BHANJI, F. et al. The Retrospective Pre-Post: A Practical Method to Evaluate Learning from an Educational Program. Academic Emergency Medicine, v. 19, n. 2, p. 189-194, 2012.

BORGES, J. L. G.; CARNIELLI, B. L. Educação e estratificação social no acesso à universidade pública. Cadernos de Pesquisa, São Paulo, v. 35, n. 124, p. 113-139, jan./abr. 2005 
DURHAM, E. R. Uma política para o ensino superior brasileiro: diagnóstico e proposta. Documentos de trabalho NUPES, v. 1, p. 98, 1998.

MAIA, R. P.; PINHEIRO, H. P.; PINHEIRO A. S. Heterogeneidade do desempenho de alunos da UNICAMP, do ingresso à conclusão. Cadernos de Pesquisa, v. 39, n. 137, maio/ago. 2009.

MENDES JÚNIOR, A. A. F. Uma análise da progressão dos alunos cotistas sob a primeira ação afirmativa brasileira no ensino superior: o caso da Universidade do Estado do Rio de Janeiro. Ensaio: aval. pol. públ. Educ., Rio de Janeiro, v.22, n. 82, p. 31 56, jan./mar. 2014.

MINISTÉRIO DA EDUCAÇÃO. PORTARIA NORMATIVA No - 18, DE 11 DE OUTUBRO DE 2012. Dispõe sobre a implementação das reservas de vagas em instituições federais de ensino de que tratam a Lei no 12.711, de 29 de agosto de 2012, e o Decreto no 7.824, de 11 de outubro de 2012. Diário Oficial da União. $\mathrm{N}^{\circ} 199$, segunda-feira, 15 de outubro de 2012.

NEVES, P. S. C.; FARO, A.; SCHMITZ, H. As ações afirmativas na Universidade Federal de Sergipe e o reconhecimento social: a face oculta das avaliações. Ensaio: aval. pol. públ. Educ., Rio de Janeiro, v.24, n. 90, p. 127-160, jan./mar. 2016.

UNIVERSIDAde fEDERAL DO TRIÂNGUlo MineIRO. Projeto Pedagógico do Curso de Medicina.2011 (atualizado em 2015). 172p. Disponível em: $<$ http://www.uftm.edu.br/upload/ensino/PPC_Medicina_2011_atualizado_em_2015.pdf $>$ WAINER, J. MELGUIZO T. Políticas de inclusão no ensino superior: avaliação do desempenho dos alunos baseado no Enade de 2012 a 2014. Educ. Pesqui., São Paulo, Ahead of print, 2017. DOI: http://dx.doi.org/10.1590/S1517-9702201612162807 